Gelanggang Olahraga: Jurnal Pendidikan Jasmani dan Olahraga

Volume 2, Nomor 1, Juli-Desember 2018

e-ISSN : 2597-6567

p-ISSN : 2614-607X

DOI : https://doi.org/10.31539/jpjo.v2i1.421

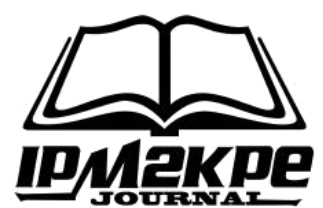

\title{
PELAKSANAAN OLAHRAGA ARUNG JERAM DI SUNGAI BATANG SANGIR KABUPATEN SOLOK SELATAN
}

\author{
Anton Komaini $^{1}$, Andri Gemaini ${ }^{2}$, Andi Syaputra ${ }^{3}$ \\ Program Studi Ilmu Keolahragaan, Universitas Negeri Padang ${ }^{1,2,3}$ \\ antonkomaini9@gmail.com ${ }^{1}$
}

\begin{abstract}
ABSTRAK
Penelitian ini bertujuan untuk mengetahui bagaimana kondisi pelaksanaan arung jeram di Kabupaten Solok Selatan dan mengetahui kondisi sumber daya alam yang ada di arung jeram Solok Selatan. Jenis penelitian ini adalah deskriptif. Penelitian ini dilakukan di lokasi arung jeram sungai Batang Sangir Kabupaten Solok Selatan, penelitian ini di lakukan pada bulan Mei - juni 2018. Populasi penelitian ini yaitu pengurus, masyarakat dan pengunjung. Teknik pengambilan sampel dilakukan dengan cara wawancara yang berjumlah 20 orang sebagai sampel. Pengambilan data di lakukan dengan wawancara, observasi dan dokumentasi. Analisis data menggunakan metode kualitatif. Berdasarkan hasil penelitian maka dapat di tarik kesimpulan sebagai berikut: 1) Sungai Batang Sangir Solok Selatan memiliki panjang lintasan arung jeram $\pm 25 \mathrm{~km}$ dan memiliki grade II, III dan bahkan pada saat curah hujan tinggi mencapai grade IV, 2) Sumber daya manusia atau pengelolaan arung jeram di Solok Selatan pada saat ini masih kurang baik, 3) Sarana dan prasarana arung jeram di Kabupaten Solok Selatan kurang memadai, dengan jumlah 1 perahu karet yang ada, dan 2 perahu karet lagi hanya sebagai pinjaman. Untuk transportasi atau jalan sudah bagus, sangat mudah untuk di lalui oleh kendaraan baik roda dua maupun roda empat.
\end{abstract}

Kata Kunci : Arung Jeram, Sungai Batang Hari

\section{ABSTRACT}

The purposes of this study are to know how the implementation of rafting and the condition of rafting natural resources in south solok regency. This is descriptive research. This research was conducted in rafting area in batang sangir river south solok regency on may until june 2018. The population were administrators, societies and visitors. The sampling technique was done by interviewing 20 people as samples. Data collection included interview, observation and documentation. Qualitative method was used in data analysis. The results of the research as follows: 1) batang sangir south solok has length of rafting track around $25 \mathrm{~km}$ in grade II, III and even grade IV in high rainfall weather. 2) human resources or rafting management in south solok regency is not good. 3) the facilities and infrastucture of rafting in south solok are inadaquate with only 1 inflatable boat available and 2 inflatable boats as loan. The transportation and road are good for motorcycles and cars.

Keyword. Rafting, Sungai Batang Hari 


\section{PENDAHULUAN}

Olahraga rekreasi merupakan sebuah aktivitas yang sangat di gemari oleh masyarakat pada saat sekarang ini, terbukti bermunculannya klub-klub dan komunitas yang menyelenggarakan kegiatan olahraga rekreasi. Kegiatan olahraga rekreasi banyak dilakukan orang ketika ada waktu luang dan ini dilakukan pada tempat/destinasi wisata yang memiliki keindahan dan kelebihan tersendiri

Suratmin (2018) menjelaskan bahwa secara umum pengertian olahraga rekreasi adalah suatu bentuk aktivitas fisik yang terencana dan terstruktur yang melibatkan gerakan tubuh berulang-ulang dan ditujukan untuk meningkatkan kebugaran jasmani.. Olahraga rekreasi tidak merujuk pada bentuk atau cabang olahraga tertentu, syarat olahraga rekreasi yaitu memenuhi norma bersama, memiliki nilai positif, sukarela, di luar jam kerja, dan mempunyai unsur pertualangan

Undang-Undang Republik Indonesia No. 3 Tahun 2005 pasal 1 ayat 4 menyebutkan bahwa "olahraga adalah segala kegiatan yang sistematis untuk mendorong, membina serta mengembangkan potensi jasmani, rohani, dan social". Lebih lengkap dalam Undang-undang No. 3 Tahun 2005 pasal 4 menyebut tujuan keolahragaan Nasional yaitu :"Keolahragaan Nasional bertujuan memelihara dan meningkatkan kesehatan dan kebugaran, prestasi kualitas manusia, menanankan nilai moral dan akhlak mulia, sportivitas, disiplin, mempererat dan membina persatuan dan kesatuan bangsa, memperkukuh ketahanan Nasional, serta mengangkat harkat, martabat dan kehormatan bangsa".

Potensi alam yang luar biasa yang dimiliki Indonesia seharusnya bisa menjadi andalan untuk mengangkat taraf hidup masyarakat. Sektor pariwisata bisa menjadi sektor penopang pemasukan negara di bidang non migas. Di era yang semakin maju semakin pula banyak cara dan strategi untuk mengangkat potensi wisata di suatu daerah. Masing-masing daerah memiliki kekhasan atau penonjolan karakteristik alam maupun sosio kultural dan aspek lainnya.

Kabupaten Solok Selatan memiliki segudang potensi rekreasi yang belum tentu di miliki oleh tempat lain, salah satunya yaitu arung jeram. Seiring berkembangnya waktu, pemerintahan Kabupaten Solok Selatan memberikan apresiasi yang baik terhadap potensi rekreasi. Salah satu olahraga yang mendorong, membina serta mengembangkan potensi jasmani, rohani dan rekreasi adalah melalui olahraga arung jeram. Selain itu, dengan olahraga arung jeram kita juga dapat mewujudkan tujuan keolahragaan nasional.

Arung jeram di Solok Selatan memiliki keunikan tersendiri, dengan kondisi wahana yang masih alami dan di sekitar jalur arung jeram terdapat bukitbukit yang masi alami dan terjaga. Arung jeram di Solok Selatan mempunyai panjang sekitar 25 kilometer, lebar sekitar 10 meter yang memiliki jeram yang cukup memberikan sensasi yang menegangkan. Setiap jeram memiliki tingkat kesulitan yang cukup menantang, dituntut keterampilan skipper agar pengunjung terhindar dari bahaya. Namun pengawasan dari penjaga juga ada, di setiap titiktitk jeram memiliki tim penolong (lifeguard) yang mengamankan keselamatan pengunjung, jika terjadi hal yang tidak di inginkan seperti perahu terbalik dan halhal lainnya. Pengelolaan wahana di Solok Selatan cukup bagus, tetapi belum ada ketentuan yang pasti atas penyelesaian wahana tersebut secara sempurna atau sesuai dengan perencanaan awal. 
Wahana arung jeram sangat jarang ditemui di tempat wisata rekreasi sehingga arung jeram merupakan nilai lebih yang menjadi fasilitas yang di gemari oleh masyaraat. Ini di karenakan arung jeram merupakan jenis rekreasi yang menantang dan memicu ardenalin serta keberanian seseorang meskipun arung jeram di kategorikan oleh raga rekreasi yang beresiko. Peserta yang akan melakukan arung jeram di berikan pengarahan tentang pengarungan sungai, dan penggunaan safety prosedur yang telah di sediakan. Setiap pengunjung yang mencoba wahana arung jeram di Kabupaten Solok Selatan harus didampingi oleh skipper (Pemandu), memakai pelampung dan pelindung kepala (helem) agar dapat mengurangi resiko yang mungkin terjadi pada saat pengarungan. Pada saat melakukan observasi oleh penulis, tantangan yang di sajikan pada wahana arung jeram ini ternyata lebih memberikan motivasi tersendiri bagi para pengunjung untuk mencoba. Wahana arung jeram telah dikenalkan ke luar daerah, dengan kemajuan teknologi yang sangat pesat ini membuat masyarakat atau pemerintah cukup mudah untuk mengenalkan ke masyarakat luar. Dengan pesatnya kemajuan teknologi sehingga baru satu bulan di resmikan pembukaan wahana arung jeram, pengunjung dari pulau jawa pernah mengunjungi wahana arung jeram di Kabupaten Solok Selatan ini.

\section{KAJIAN TEORI}

\section{Kegiatan Rekreasi}

Herbert Hagg (1994) Recreational sport/leisure time sports are formd of physical activity in leisure under a time perspective. It comprises sport after work, on weekends, in vacations, in retirement, or during periods of (unfortunate unemployment).Dapat disimpulkan bahwa olahraga rekreasi adalah sebuah aktivitas dan kegiatan yang direncanakan secara matang dan terencana, namun tidak memiliki aturan yang terlalu mengikat, dikerjakan atas keinginan sendiri, dilakukan pada waktu luang yang tujuannya adalah mendapatkan kesenangan, rileks, dan kebugaran"

Rosmaneli (2012) menjelaskan bahwa tujuan berekreasi adalah untuk memulihkan keseimbangan pikiran, penyegaran badan, mendapatkan kepuasan agar tercipta suasana baru, dan meningkatkan produktivitas kerja. Manfaat sama dengan artinya dengan guna, faedah atau keuntungan melakukan sesuatu. Adapun motif untuk berekreasi adalah sebagai berikut: 1) montoni keseharian, setiap hari ada dalam lingkungan yang sama dalam situasi yang sama pula dengan pergaulan yang sangat terbatas; 2) Jenuh, pekerjaaan yang rutin sangat membosankan dan sampai menekan, setidaknya selama sepekan untuk kemudian berulang di minggu mendatang; 3) Kesepian dan keramaian, pergaulan baik di rumah maupun di pekerjaan sangat terbatas; 4) Potensi yang terpendam, memerlukan penyaluran dan jika tidak disalurkan akan menjadi beban (Suratmin: 2018).

Begitu pula dengan kegiatan rekreasi, juga memiliki berbagai manfaat atau keuntungan menurut Tim Rekreasi UNP yaitu sebagai berikut: a) Mendatangan kebahagiaan, Kebahagiaan merupakan suatu yang mencerminkan perasaan senang dan tentram, bebas dari segala hal yang menyusahkan, baik lahir maupun batin. Ketika berekreasi ke suatu tempat wisata atau panorama alam yang indah disertai dengan udara yang sejuk dan nyaman. Badan terasa segar, pikiran akan tenanga dan dapat melupakan segala hal yang menyusahkan hatinya. Perasaan jasmani yang segar karena barada di alam yang tentram akan mendatangkan kebahagiaan, 
b) menimbulkan kepuasan, kepuasan yang diperoleh dari kegiatan rekreasi erat dengan hubunganya dengan perasaan senang, gembira atau bahagia sebagaimana di kemukakan diatas. Dengan kata lain, seorang akan merasa puas karena telah mendapatkan kesenangan, puas karena telah memperoleh kegembiraan, dan puas karena telah merasakan kebahagiaan, c)Membantu perkembangan yang seimbang, manusia terbentuk dari jasmani dan rohani, jasmani disebut juga dengan istilah raga, fisik dan badan. Sementara itu, rohani disebut juga dengan jiwa,psikis, dan mental. Baik jasmani maupun rohani sama-sama memiliki keinginan atau kebutuhan tertentu.

\section{Arung Jeram}

Darsono dan Setia dalam Setiawan (2015), arung jeram adalah aktivitas pengarungan bagian alur sungai yang berjeram atau riam dengan menggunakan wahana tertentu. Pengertian wahana dalam hal ini adalah sarana atau alat yang terdiri atas perahu karet, kayak, kano,dan dayung. Tujuan berarung jeram bisa dilihat dari sisi olahraga, rekreasi, dan ekspedisi. Dengan demikian, kita dapat mendefenisikan olahraga arung jeram sebagai olahraga mengarungi sungai berjeram dengan menggunakan perahu karet, kayak, kano, dan dayung dengan tujuan rekreasi atau ekspedisi.

Arung jeram atau Rafting adalah sebuah aktifitas yang memadukan unsur petualangan adventure, edukasi, olahraga, dan rekreasi dengan mengarungi alur sungai yang ber 'jeram' menggunakan boat karet, dayung, kayak, dan kano. Selain menguji nyali, aktifitas rafting juga berisiko namun asal setia mengikuti aba-aba yang diberikan pemandu, maka semua akan aman-aman saja.

Suratmin (2018) menjelaskan bahwa Arung jeram adalah kegiatan yang memacu adrenalin sekaligus aman, snagat cocok bagi pemula maupun yang sudah mahir Menurut Darsono dan Setria (2008). Kondisi yang menyatakan sulittidaknya sungai berjeram ditunjukan melalui skala tingkat kesulitan sungai. Ada dua skala yang dikenal dalam olahraga arung jeram yaitu: 1) International scale, angka ukuran adalah I-VI. I berarti mudah, sedangkan VI berarti amat sulit dan tidak mungkin dilalui. Angka skala kesulitan ini berlaku dan digunakan di sungaisungai Amerika Utara dan dartan Eropa, 2) Wastern scale, angka skala ini diperkenalkan oleh penguasa Grand Canyon di Amerika, Doc Marston. Ukuranya berkisar antara 1-10.

Safety atau keamanan ini adalah hal yang sangat penting dalam melakukan aktivitas apapun, yang mana dalam melakukan sesuatu yang belum tahu apakah itu aman atau tidak, biasanya akan muncul rasa takut, tetapi bila melakukan sesuatu yang memang di anggap aman maka, kita pun akan bisa melakukannya dengan lebih percaya diri. Apabila kita selalu melakukan pencegahan maka kecelakaan apapun akan sangat minim artinya mengetahui ilmu keamanan lebih prioritas dari ilmu penyelamatan (Brown, 2015)

\section{METODE PENELITIAN}

Jenis penelitian ini adalah jenis penelitian kualitatif yang bersifat deskriptif. Sugiyono (2008) kualitatif adalah metode penelitian yang berlandaskan pada filsafat postpositivisme, untuk meneliti pada kondisi obyek yang alamiah, dimana peneliti adalah sebagai instrumen kunci, pengambilan sampel sumber data dilakukan secara purposive dan snowbaal, teknik pengumpulan dengan triangulasi 
(gabungan), analisis data bersifat induktif/kualitatif. Penelitian ini dilakukan di wahana arung jeram Sungai Batang Sangir Kabupaten Solok Selatan. Waktu penelitian dilakukan bulan Mei-Juli 2018. Sumber data dalam penelitian ini adalah Kelompok Sadar Wisata Mundam Sakti, Dinas Pemuda Olahraga dan Pariwisata Kab. Solok Selatan, pengunjung wahana arung jeram, dan masyarakat sekitar. Instrumen penelitian dengan menggunakan teknik wawancara langsung dan terbuka, observasi dan studi dokumentasi. Prosedur penelitian, pengumpulan data, triangulasi data dan penarikan kesimpulan.

\section{HASIL PENELITIAN}

Pembahasan akan dilakukan berdasarkan hasil dari wawancara informasi yang berjumlah 20 orang. Informasi dari penelitian ini adalah pengelola dan masyarakat di lokasi arung jeram Kabupaten Solok Selatan, peneliti melakukan penelitian dengan mengajukan pertanyaan kepada narasumber tentang kondisi arung jeram di Kabupaten Solok Selatan.

\section{Kondisi Arung Jeram di Sungai Batang Sangir Kabupaten Solok Selatan (SDA)}

Tabel 1.

Karakteristik Sungai Batang Sangir Kabupaten Solok Selatan

\begin{tabular}{llll}
\hline $\begin{array}{l}\text { Rata-Rata Besar } \\
\text { Aliran }(\mathrm{m} 3 / \mathrm{det})\end{array}$ & $\begin{array}{l}\text { Rata- Rata Aliran } \\
(\mathrm{it} / \mathrm{det} / \mathrm{km} 2)(\mathrm{m} / \mathrm{km})\end{array}$ & $\begin{array}{l}\text { Tinggi Aliran } \\
(\mathrm{mm})\end{array}$ & $\begin{array}{l}\text { Volume Air } \\
\text { (juta m3 ) }\end{array}$ \\
\hline 30,28 & 13,40 & 432,55 & 956,40 \\
\hline
\end{tabular}

Dalam data tabel di atas memberikan informasi mengenasungai Batang Sangir, tetapi data di atas tidak dapat di jadikan patokan sebenarnya karena debit air sungai Batang Sangir tidak menentu, tergantung curah hujan dan cuaca kemarau. Dan jika terjadi cura hujan yang tinggi di hulu maka debit air sungai Batang Sangir akan meningkat pesat. Panjang sungai atau jalur yang di pakai untuk arung jeram di sungai Batang Sangir Kabupaten Solok selatan $\pm 25 \mathrm{Km}$, tetapi yang biasa digunakan untuk wisata hanya sekitar $\pm 15 \mathrm{Km}$ dan yang paling.

Grade jeram pada saat tidak musim hujan atau kemarau di sungai Batang Sangir yaitu grade II dan grade III dan pada saat musim hujan yaitu mencapai grade IV. Pada saat musim hujan terkadang pengunjung tidak di perbolehkan untuk turun ke sungai, karena menurut masyarakat sekitar lidah air sering terjadi pada saat musim hujan di hulu. Kelompok sadar wisata Mundam Sati mengkhawatirkan kondisi jalur arung jeram di sepanjang sungai Batang Sangir Solok Selatan, Sumatra Barat akan semakin rusak dan menglami pendangkalan. Hal ini terjadi karena telah dialih fungsikan oleh perusahaan Pembangkit Listrik Tenaga Mikro Hidro (PLTMH) sebagai lokasi bendungan dan pembangkit. Kondisi seperti ini berdampak berkurangnya spot terbaik yang ada di Solok Selatan, dan untuk sekarang ini arung jeram Solok Selatan telah kehilangan spot jeram ekstrim. 


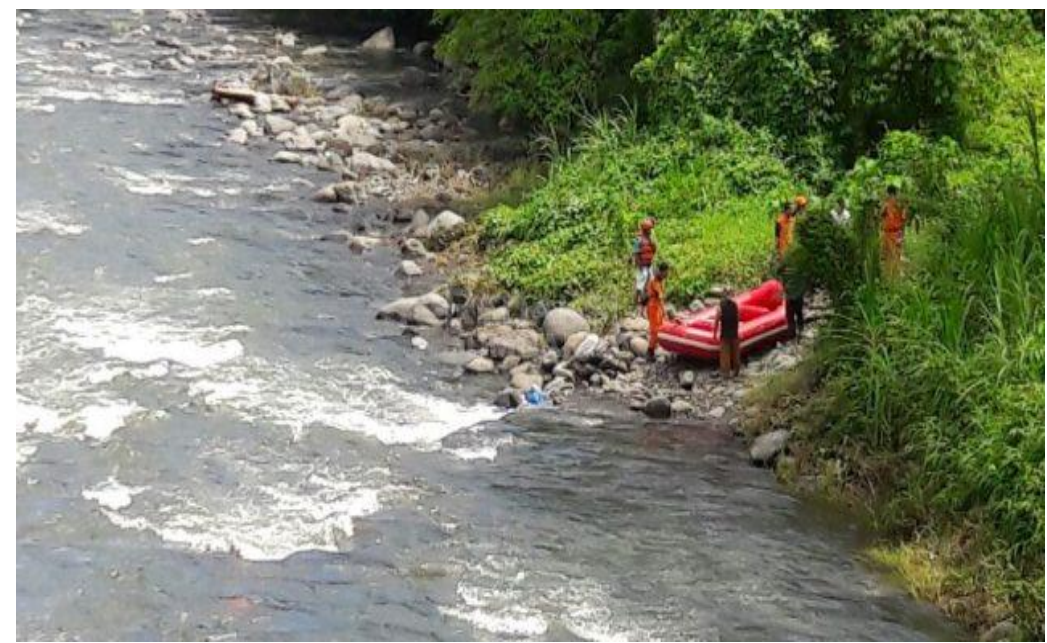

Gambar 1. Titik Star arung jeram

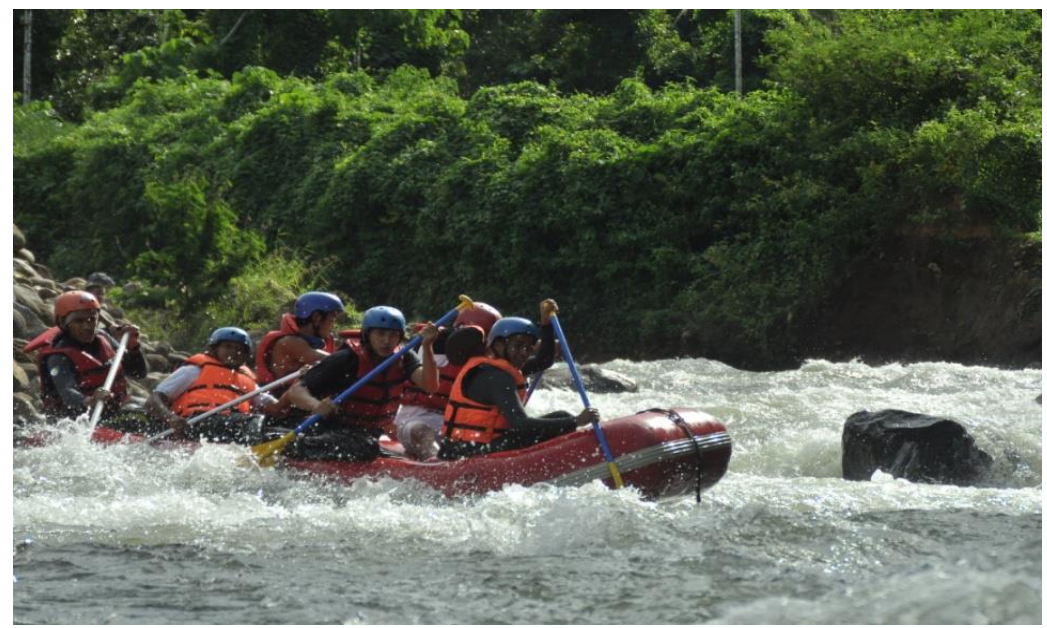

Gambar 2. Jeram sungai Batang Sangir (Grade II)

\section{Pengelolaan Arung Jeram Sungai Batang Sangir (SDM)}

Sumber daya manusia merupakan salah satu faktor yang sangat penting dalam sebuah organisasi, sumber daya manusia juga merupakan kunci yang menentukan perkembangan suatu perusahaan. Pada hakikatnya sumber daya manusia berupa manusia yang diperkerjakan di sebuah organisasi sebagai penggerak, pemikir dan perencana untuk mencapai tujuan agar lebih baik lagi. Adapun susunan pengurus kelompok sadar wisata Solok Selatan terdapat 19 orang pengurus arung jeram atau di sebut sebagai kelompok sadar wisata arung jeram di sungai Batang Sangir Kabupaten Solok Selatan oleh kelompok sadar wisata mundam sati. Olahraga rekreasi arung jeram di latih oleh anggota FAJI Solok Selatan Aig Wadenko.

\section{Sarana dan Prasara Olahraga Rekreasi Arung Jeram di Sungai Batang Sangir}

Batang Sangir mempunyai pemandangan yang bagus dan alami. Sungai Batang Sangir dengan pemandangan yang menakjubkan sepanjang jalan. Mulai 
dari komposisi perbukitan yang menjulang dengan kokoh di pinggiran sungai, yang ditumbuhi pohon-pohon alami sehingga membuat pengunjung merasakan indahnya alam yang masih alami ini.

Arung jeram ini dikelola oleh Kelompok Sadar Wisata (pokdarwis) Mundam Sati Rafting Solok Selatan yang diketuai oleh Eko Irawan, berdiri pada tanggal 7 Februari 2015. Pokdarwis tersebut memiliki kegiatan meliputi mengarungi arus sungai di Solok Selatan dengan perahu karet dan beberapa kegiatan sosial lainnya seperti pembersihan jalur sungai. Karakter sungai di Solok Selatan sangat menantang, dengan lintasan yang cukup panjang sekitar $25 \mathrm{~km}$. Ditambah lagi dengan pemandangan yang sangat cantik di sekitar sungai. Potensi ini tidak ada di daerah-daerah lainnya. Saat ini kelompok sadar wisata (pokdarwis) baru memiliki satu buah perahu karet.

Akses jalan untuk menuju lokasi arung jeram di Kabupaten Solok Selatan ini tidak memakan waktu yang begitu lama, karena lokasi arung jeram sungai Batang Sangir ini berada tidak jauh dari jalan lintas, untuk menuju kelokasi hanya membutuhkan waktu \pm 15 menit saja dari jalan lintas. Dengan akses jalan yang tidak memakan banyak waktu itu membuat pengunjung ingin menikmati arung jeram di Solok Selatan.)

Adapun sarana prasarana arung jeram yang ada di Solok Selatan adalah: Perahu karet yang terdapat pada arung jeram sungai batang sangir (kelompok sadar wisata) berjumlah 1 buah perahu karet dan dinas pariwisata pemuda dan olahraga 2.

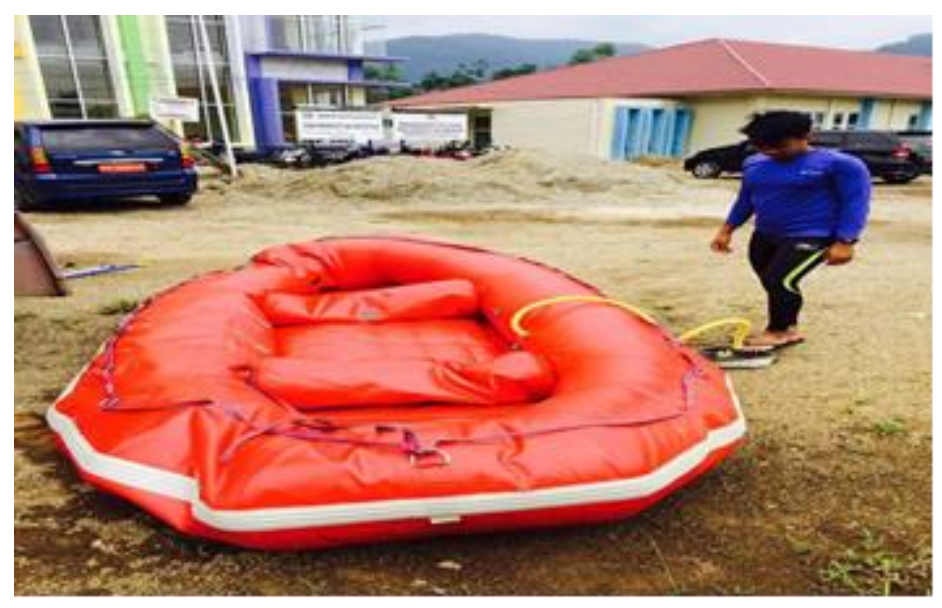

Gambar 3. Perahu karet arung jeram Solok Selatan

Jumlah tali penyelamat ada satu gulungan, perlengkapan P3K satu kotak. Pelampung yang terdapat pada arung jeram Sungai Batang Sangir lengkap, tetapi masih belum memenuhi standar berarung jeram. Helm yang terdapat pada arung jeram sungai batang sangir lengkap, tetapi helm yang digunakan belum termasuk standar arung jeram. 


\section{PEMBAHASAN}

Berdasarkan hasil penelitian didapatkan hasil 1) Sumber daya alam dari olahraga rekreasi arung jeram di sungai Batang Sangir sangat bagus di jadikan olahraga rekreasi arung jeram, mempunyai grade-grade II, III, dan Bahkan mencapai grade IV terjadi pada saat musim hujan dan juga pemandangan alam yang indah 2) Sumber daya manusia dari olahraga rekreasi arung jeram di sungai Batang sudah tersedia, ketersediaan ini membuka peluang yaitu dapat membuka peluang usaha, peningkatan pendapatan pedagang, pengetahuan masyarakat bertambah, terbentuknya organisasi kelompok sadar wisata Mundam Sati arung jeram dengan tujuan untuk mengembangkan olahraga rekreasi arung jeram di sungai Batang Sangir dan manajemen belum terlakasana dengan baik, 3) Sarana dan prasarana olahraga rekreasi arung jeram di Solok Selatan berada dalam kategori kurang.bahwa manajemen olahraga rekreasi arung di sungai batang sangir belum terlaksana dengan baik, tentang pengawasan sarana dan prasarana melum mempunyai jadwal yang permanen. Dan dalam pengelolaan terbentur pada bantuan yang masih minim di berikan oleh pemerintah, sehingga membuat penjagaan dan perawatannya tidak terlaksana dengan baik.

Olahraga Arung Jeram sangat potensial dikembangkan di Sungai Batang Sangir. Untuk mendukung pengembangan olahraga arung jeram ini ada beberapa hal yang perlu disiapkan, diantaranya adalah penyiapan Sumber Daya Manusia. Dala, penyiapan sumber daya manusia perlua adanay perhatian Pemerintah Kabupaten Solok Selatan dengan dibantu swadaya masyarakat dalam menyiapkan pelatihan-pelatihan khusus untuk pelatihan pemandu dalam olahraga rekreaasi Arung Jeram.

Dalam hal sarana dan prasarana perlu adanya penganggaran khusus dari pihak yang terkai untuk mengembangkan potensi Arung Jeram ini. Perlu adanya pengadaan infrastruktur secara bertahap dan pengadaaan prasarana dalam mendukun potensi ini. Manfaat yang bisa diambil ketika wahana arung jeram ini berkembang antara lain, dari segi pengetahuan masyarakat juga bisa berkembang dengan adanya masyarakat luar masuk, denngan ada olahraga rekreasi arung jeram di sungai batang sangir, masyarakat bisa belajar bagai mana pentingnya melestarikan alam sekitar dan menjaganya, sehingga tidak terjadi lagi penambangan yang illegal dan penebangan hutan yang tidak memiliki izin resmi. Dengan adanya olahraga rekreasi arung jeram maka terbentuk lah suatu organisasi yang di namakan kelompok sadarwisata Mundam sati. Adanya olahraga rekreasi arung jeram memerlukan pengurus khusus, agar adanya kemajuan untuk olahraga rekreasi arung jeram tersebut.

\section{SIMPULAN}

Berdasarkan hasil penelitian tentang Tinjauan Olahraga Rekreasi Arung Jeram Di Sungai Batang Sangir Kabupaten Solok Selatan maka dapat diambil kesimpulan sebagai berikut; sumber daya alam dari olahraga rekreasi arung jeram di sungai Batang Sangir sangat bagus di jadikan olahraga rekreasi arung jeram, mempunyai grade-grade II, III, dan Bahkan mencapai grade IV terjadi pada saat musim hujan dan juga pemandangan alam yang indah. Sumber daya manusia dari olahraga rekreasi arung jeram di sungai Batang sudah tersedia, ketersediaan ini membuka peluang yaitu dapat membuka peluang usaha, peningkatan pendapatan pedagang, pengetahuan masyarakat bertambah, terbentuknya organisasi kelompok 
sadar wisata Mundam Sati arung jeram dengan tujuan untuk mengembangkan olahraga rekreasi arung jeram di sungai Batang Sangir dan manajemen belum terlakasana dengan baik.. Sarana dan prasarana olahraga rekreasi arung jeram di Solok Selatan berada dalam kategori kurang.

\section{DAFTAR PUSTAKA}

Darsono \& Satria. (2008). Olahraga Alam. Jakarta: PT Percia.

Haag, H. (1994). Comparative Physical Education and sport. Human Kinetics Publishers.

Made, B, (2015). Panduan Keamanan Arung Jeram untuk Pemula, Operator dan Profesiona. Bali: PANAKOM

Rosmaneli \& Seprinaldi, (2014). Konsep dasar pendidikan rekreasi. Padang: FIK UNP.

Setiawan, A. (2015). Industri Olahraga Rekreasi Arung Jeram di Kabupaten Banjarnegara.(Laporan Penelitian). Universitas Negeri Semarang. 20 Desember 2017.

Sugioyono. (2008). Metode Penelitian Kuantitatif dan Kualitatif dan R\&D. Alfabeta Bandung.

Suratmin. (2018). Pengantar Olahraga Rekreasi dan Olahraga Pariwisata. Depok. Raja Grafindo Persada.

Tim Mata Kuliah Rekreasi, (2016) Olahraga Rekreasi. Padang: FIK Universitas Negeri Padang(UNP)

Undang-undang Republik Indonesia No 3 Tahun 2005, Tentang Sistem Keolahragaan Nasional, Jakarta, Dirjen Pendidikan Dasar dan Menengah. 